\title{
Elaboração e validação de escala diagramática para avaliação da pústula bacteriana em soja
}

\author{
Laura Feuser Acco $^{1} \oplus$, Diego Genuário Gomes ${ }^{1} \oplus$, Janaina Netzel Matos ${ }^{2} \oplus$, Neucimara Rodrigues Ribeiro² ${ }^{\circledR}$, \\ Maria Isabel Balbi-Peña ${ }^{3}$ CD
}

\begin{abstract}
${ }^{1}$ Programa de Pós-graduação em Agronomia, Universidade Estadual de Londrina, Londrina, Rodovia Celso Garcia Cid, PR 445, Km 380, Campus Universitário, Cx. Postal 10.011, CEP 86.057-970, Londrina-PR, Brasil. ${ }^{2}$ GDM SEEDS do Brasil, Rua Antonio Rasteiro Filho, 2700 - Parque Industrial José Garcia Gimenez, CEP 86183-751, Cambé-PR, Brasil. ${ }^{3}$ Professora, Programa de Pós-graduação em Agronomia, Universidade Estadual de Londrina, Londrina, Rodovia Celso Garcia Cid, PR 445, Km 380, Campus Universitário, Cx. Postal 10.011, CEP 86.057-970, Londrina-PR, Brasil.

Autor para correspondência: Maria Isabel Balbi-Peña (mariabalbi@uel.br).

Data de chegada: 14/08/2018. Aceito para publicação em: 23/01/2020.
\end{abstract}

$10.1590 / 0100-5405 / 211476$

\section{RESUMO}

Acco, L.F.; Gomes, D.G.; Matos, J.N.; Ribeiro, N.R.; Balbi-Peña, M.I. Elaboração e validação de escala diagramática para avaliação da pústula bacteriana em soja. Summa Phytopathologica, v.46, n.2, p.145-149, 2020.

A pústula bacteriana, causada pela bactéria Xanthomonas axonopodis pv. glycines, é considerada uma das mais sérias doenças bacterianas na cultura da soja. O objetivo deste trabalho foi desenvolver e validar uma escala diagramática para a avaliação da severidade da pústula bacteriana em soja. Para a elaboração da escala, foram coletados folíolos de soja com diferentes níveis de severidade, determinando assim os valores máximos e mínimos de quantidade de doença, e os níveis intermediários de severidade da escala foram estabelecidos de acordo com a lei do estímulo visual de Weber-Fechner. Os valores propostos para a escala foram: $1,4 \% ; 3 \%$; $6 \% ; 9 \% ; 20 \%$ e $29,5 \%$. Para validação da escala, oito avaliadores, sem experiência na avaliação da doença, avaliaram 39 fotos com diferentes níveis de severidade, sem e com o auxílio da escala. Os resultados das severidades estimadas pelos avaliadores foram relacionados com os valores das severidades reais (determinadas com o software Assess 2.0 a partir de imagens digitais das folhas com sintomas) e submetidos a regressões lineares simples para avaliar a acurácia dos avaliadores. A precisão dos avaliadores foi determinada através dos coeficientes de determinação e da variância dos erros absolutos. As estimativas com o uso da escala diagramática proposta determinaram um aumento significativo do coeficiente de determinação e uma menor variância dos erros absolutos, proporcionando maior precisão e acurácia das avaliações, podendo ser adotada para a avaliação da severidade da pústula bacteriana em soja.

Palavras-chave: Glycine max (L.) Merrill; Doenças foliares da soja; Patometria; Xanthomonas axonopodis pv. glycines.

\section{ABSTRACT}

Acco, L.F.; Gomes, D.G.; Matos, J.N.; Ribeiro, N.R.; Balbi-Peña, M.I. Elaboration and validation of a digrammatic scale to evaluate soybean bacterial pustule. Summa Phytopathologica, v.46, n.2, p.145-149, 2020.

Bacterial pustule, caused by the bacterium Xanthomonas axonopodis pv. glycines, is considered one of the most important bacterial diseases affecting soybean. The aim of this study was to develop and validate a diagrammatic scale for assessing the severity of soybean bacterial pustule. To elaborate the scale, soybean leaflets with different severity levels were collected to determine the maximum and minimum values of disease severity, while intermediate levels were established according to Weber-Fechner law of visual stimulus. The values proposed for the scale were $1.4 \%, 3 \%, 6 \%, 9 \%$, $20 \%$ and $29.5 \%$. To validate the scale, eight evaluators, with no experience in bacterial pustule evaluation, assessed 39 photos of leaflets with different severity levels, without and with the aid of the scale. The results of severity estimated by the evaluators were related to the actual severity values (determined with Assess 2.0 software from digital images of leaves with symptoms) and analyzed with simple linear regressions to assess the accuracy of evaluators. The precision of evaluators was determined based on the coefficients of determination and the variance in absolute errors. Estimates using the proposed diagrammatic scale indicated a significant increase in the coefficient of determination and lower variance in absolute errors, providing greater precision and accuracy of evaluations, which could be adopted to assess the severity of soybean bacterial pustule.

Keywords: Glycine max (L.) Merrill; Foliar diseases of soybean; Pathometry; Xanthomonas axonopodis pv. glycines.

A pústula bacteriana causada pela bactéria Xanthomonas axonopodis pv. glycines é considerada uma das mais sérias doenças bacterianas na cultura da soja (3). Os sintomas da doença são tipicamente expressos nas folhas, iniciando-se por pequenas manchas de coloração verde-amarelada com o centro elevado de cor amarelopalha, que se tornam necróticas em pouco tempo. As manchas são geralmente circundadas com estreito halo amarelo que pode alargar-se nas lesões mais velhas (5).

No Brasil, não há estudos sobre perdas e danos causados pela doença, mas em outros países os danos estimados podem variar de
$11 \%$ a $40 \%$ (7). Sain \& Gour (10) relatam a incidência severa da pústula bacteriana na Índia, causando reduções de produtividade de até $32,7 \%$ relacionadas a infecções via semente e via foliar, que reduzem o tamanho e o número de grãos da soja. Quando presente, é uma doença de difícil manejo pois o controle utilizando produtos químicos é ineficiente (7).

Na década de 1950 foi descoberto que a cultivar CNS era resistente à pústula bacteriana. Através da incorporação do gene recessivo rxp em várias linhagens foram desenvolvidas cultivares resistentes à doença. Devido à durabilidade e à simplicidade do uso deste gene não tem 
havido extensas buscas de outras fontes de resistência (13). O uso de cultivares resistentes é o único controle efetivo em áreas com presença do patógeno (14). A maioria das cultivares de soja comercializadas no Brasil apresentam resistência à pústula bacteriana (9), mas cultivares para uso específico na alimentação humana são suscetíveis à doença (15) A partir da década de 2000, foi observada esporadicamente a incidência da pústula bacteriana no campo. Na safra 2007/2008, em monitoramento de 16 áreas produtoras de soja no estado do Paraná, Bonaldo et al. (2) relataram a ocorrência da doença em 15,01\% das lavouras analisadas. A introdução clandestina de cultivares transgênicas, o uso de germoplasmas provenientes dos Estados Unidos e do Oriente, onde a pústula bacteriana não é considerada importante, e o uso continuado de uma única fonte de resistência à doença, têm sido apontados como causas desse reaparecimento $(7,15)$.

A severidade é a variável mais utilizada para a quantificação de doenças foliares, a qual pode ser estimada por análises visuais. Ferramentas como chaves descritivas, escalas diagramáticas e análises de imagens digitais têm sido propostas para a avaliação da severidade de doenças. Escalas diagramáticas são representações ilustradas de uma série de plantas ou partes de plantas com sintomas da doença em diferentes níveis de severidade, minimizando a subjetividade causada pela avaliação visual (1). Amorim \& Bergamin Filho (1) descrevem que as escalas diagramáticas são um guia para o avaliador, e quando há necessidade de avaliações muito precisas, o avaliador deve ser treinado, pois frequentemente a vista humana superestima a doença. A elaboração de uma escala deve considerar os limites superiores e inferiores correlacionando-os com a máxima e mínima intensidade da doença observada no campo e os sintomas devem ser os mais próximos possíveis dos observados. Segundo Horsfall \& Barratt (6), os níveis intermediários da doença devem ser estabelecidos considerando as limitações de acuidade do olho humano definidas pela lei de estímulosresposta de Weber-Fechner.

Atualmente na literatura não existe uma escala diagramática para a avaliação e quantificação da pústula bacteriana em soja e, portanto, o objetivo deste trabalho é a elaboração e a validação dessa escala.

\section{MATERIAL E MÉTODOS}

Para a realização do ensaio foram coletados 100 trifólios de soja de uma linhagem voltada para alimentação humana (NT 12), a qual apresenta reação suscetível a doença. Os trifólios, com diferentes níveis de severidade, foram coletados em campo e casa de vegetação. (GDM SEEDS do Brasil, Cambé-PR).

A partir desses trifólios, foram obtidas imagens por meio de fotografia digital e as imagens foram analisadas no software Assess 2.0, que calculou a porcentagem de área foliar com sintomas (severidade real da doença). Considerando um valor mínimo e máximo de severidade, determinaram-se os valores intermediários de severidade da escala, baseados na lei de Weber-Fechner de estímulo visual. Foram utilizadas imagens reais de folíolos na elaboração da escala. As fotos foram previamente tratadas com programa de edição de fotos, realçando o brilho, contraste, e redimensionadas para um tamanho de $640 \times 480$ pixels, para melhor reconhecimento dos sintomas pelo programa Assess 2.0.

A validação da escala foi feita por meio de uma apresentação em slides com 39 fotografias de folíolos apresentando diferentes níveis de severidade da doença. A apresentação foi avaliada por oito pessoas consideradas sem experiência na quantificação desta doença.
Primeiramente, a avaliação foi feita sem a utilização da escala, e em seguida com a utilização da mesma.

Os resultados de severidade estimada pelos oito avaliadores, com e sem a escala, foram comparados com a severidade real para se determinar a precisão das avaliações. Foi aplicado o método da análise de regressão linear, considerando a inclinação da reta de regressão igual a uma constante 1 . O modelo da regressão e as hipóteses apropriadas para avaliar a severidade da pústula bacteriana em folíolos de soja, considerando uma distribuição de probabilidade normal, são os que seguem:

$$
\text { Seja o modelo } \quad Y_{i}=a+b x+\varepsilon_{i}
$$

Em que $Y_{i}$ é a variável dependente ou a severidade obtida pelos avaliadores; $a$ é o intercepto ou coeficiente linear; $b$ é o coeficiente angular ou inclinação da reta de regressão; $x$ é a variável independente ou a severidade real da pústula bacteriana e, $\varepsilon_{i}$ são os erros com distribuição normal, $\left(\mathrm{N} \approx 0, \sigma^{2}\right)$. Os coeficientes $a$ e $b$ são constantes desconhecidas e que doravante serão denominados parâmetros da equação de regressão linear e $x$ é uma constante conhecida.

A acurácia das estimativas dos avaliadores foi determinada pela aplicação do teste $t(\mathrm{P} \leq 0,05)$ aos coeficientes da regressão linear $\left(H_{0}\right.$ : $a=0$ e $\left.H_{0}: b=1\right)$. A precisão das estimativas foi avaliada através do coeficiente de determinação $\left(\mathrm{R}^{2}\right)$ e pela variância dos erros absolutos. Os erros absolutos foram calculados subtraindo a severidade real da severidade estimada. As análises estatísticas foram realizadas com o software computacional R (R Development Core Team, 2010).

\section{RESULTADOS E DICUSSÃO}

Seis valores de severidade compõem a escala diagramática proposta: $1,4 \% ; 3 \% ; 6 \% ; 9 \% ; 20 \%$ e 29,5\% (Figura 1). No teste de validação os avaliadores apresentaram maior precisão nas suas avaliações quando utilizaram a escala diagramática.

Os resultados do teste $t$ para os coeficientes lineares (a) sem o uso da escala foram significativamente diferentes de zero, exceto para o sétimo avaliador (Tabela1). Todos os demais avaliadores foram pouco acurados na avaliação da severidade da pústula bacteriana para as retas de regressão, apresentando um valor médio de coeficiente linear de 8,6. Já com uso da escala proposta, a análise da acurácia indicou coeficientes lineares não significativos para todos os avaliadores exceto o avaliador 1 .

A análise de precisão, estimada pelo coeficiente de determinação $\left(\mathrm{R}^{2}\right)$, indicou valores entre 0,36 e 0,66 , com média de 0,52 para a estimativa sem escala e valores entre 0,72 e 0,96 , com média de 0,87 para a estimativa com a escala (Tabela1). Verificou-se maior confiabilidade na avaliação da doença com a escala, pois houve aumento expressivo nos valores dos coeficientes $\mathrm{R}^{2}$.

Em relação aos erros absolutos (severidade estimada menos severidade real), com a utilização da escala os avaliadores apresentaram maior tendência em subestimar os valores de severidade (Tabela 2; Figura 2). No entanto, sem a utilização da escala as estimativas refletiram em valores superestimados quando comparados com a severidade real da doença.

De acordo com os dados apresentados na Tabela 2, pode-se fazer a interpretação de que o avaliador 4, por exemplo, sem o uso da escala superestimou a quantidade de doença em 31 e subestimou em oito avaliações. A dispersão destes erros ocorreu entre -2,36 e 22,40. 


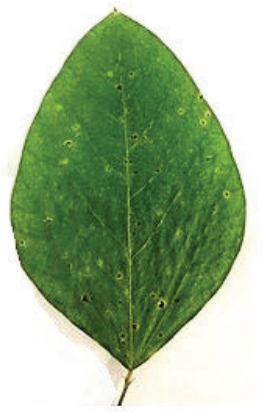

$1,4 \%$

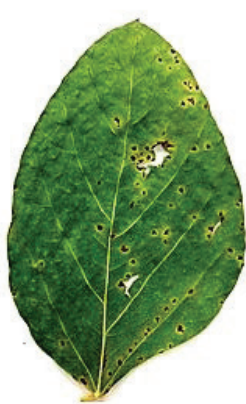

$3 \%$

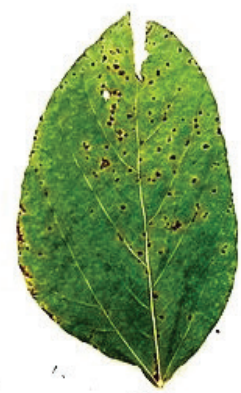

$6 \%$

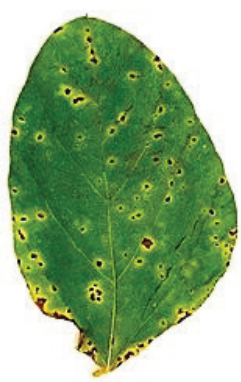

$9 \%$

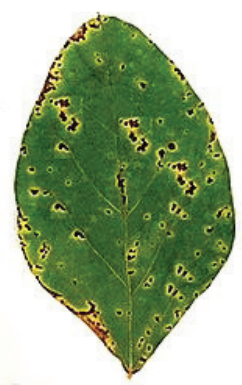

$20 \%$

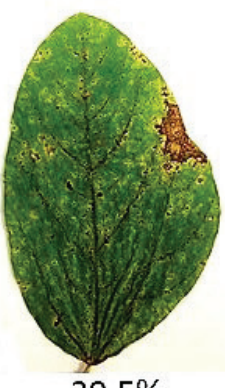

$29,5 \%$

Figura 1. Escala diagramática para avaliação da pústula bacteriana da soja.

Tabela 1. Valores estimados e teste $t$ para os parâmetros intercepto ou coeficiente linear $(a)$, coeficiente angular $(b)$, valores dos coeficientes de determinação $\left(\mathrm{R}^{2}\right)$ para o modelo de regressão linear comparando a severidade real da pústula bacteriana com a estimada, com o uso ou não da escala diagramática

\begin{tabular}{|c|c|c|c|c|c|c|c|c|c|c|}
\hline \multirow{3}{*}{ Avaliador } & \multicolumn{5}{|c|}{ Sem escala diagramática } & \multicolumn{5}{|c|}{ Com escala diagramática } \\
\hline & \multicolumn{2}{|c|}{ Estimativa } & \multicolumn{2}{|c|}{$\begin{array}{l}\text { Valores do teste } t \\
\text { para o parâmetro }\end{array}$} & \multirow{2}{*}{$\begin{array}{c}\begin{array}{c}\text { Coef. de } \\
\text { Determ. }\end{array} \\
\mathrm{R}^{2} \\
\end{array}$} & \multicolumn{2}{|c|}{ Estimativa } & \multicolumn{2}{|c|}{$\begin{array}{l}\text { Valores do teste } t \\
\text { para o parâmetro }\end{array}$} & \multirow{2}{*}{$\begin{array}{c}\text { Coef. de } \\
\text { Determ. } \\
R^{2}\end{array}$} \\
\hline & $a$ & $b$ & $a$ & $b$ & & $a$ & $b$ & $a$ & $b$ & \\
\hline 1 & $15.78 * *$ & $1.43 * *$ & 5.18 & 4.73 & 0.38 & $-0.92 *$ & $1.06 * *$ & -2.68 & 31.17 & 0.96 \\
\hline 2 & $13.29 * *$ & $1.48 * *$ & 4.10 & 4.58 & 0.36 & $0.10^{\mathrm{ns}}$ & $0.91 * *$ & 0.15 & 13.76 & 0.84 \\
\hline 3 & $5.84 * *$ & $1.59 * *$ & 3.10 & 8.49 & 0.66 & $0.25 \mathrm{~ns}$ & $0.91 * *$ & 0.26 & 9.68 & 0.72 \\
\hline 5 & $10.33 * *$ & $1.67 * *$ & 3.86 & 6.30 & 0.52 & $-0.32 \mathrm{~ns}$ & $1.00 * *$ & -0.72 & 22.61 & 0.93 \\
\hline 6 & $10.60 * *$ & $1.41 * *$ & 4.97 & 6.65 & 0.54 & $-0.58^{n s}$ & $1.03 * *$ & -1.40 & 25.03 & 0.94 \\
\hline 7 & $2.94 \mathrm{~ns}$ & $1.74 * *$ & 1.12 & 6.66 & 0.55 & $0.10^{\mathrm{ns}}$ & $0.91 * *$ & 0.15 & 13.76 & 0.84 \\
\hline 8 & $5.96 * *$ & $1.30 * *$ & 3.23 & 7.06 & 0.57 & $0.25^{\mathrm{ns}}$ & $1.01 * *$ & 0.29 & 11.87 & 0.79 \\
\hline
\end{tabular}

** Valores do teste $t$ significativo ao nível de $1 \%$ de probabilidade $(\mathrm{p} \leq 0.01) ;{ }^{*}$ valores do teste $t$ significativo ao nível de $5 \%$ de probabilidade $(\mathrm{p} \leq 0.05) ;{ }^{\text {ns }}$ não significativo. Os valores críticos para o teste $t$ ao nível de $1 \%$ e $5 \%$ com 37 graus de liberdade são os que seguem: $t_{(0.01 ; 37 \mathrm{gl})}=2.711 \mathrm{e} t_{(0.05 ; 37 \mathrm{gl})}=2.023$

Tabela 2. Intervalo de variação dos erros ([ ] ERRos), estimativas dos parâmetros obtidas por meio dos resíduos da análise de regressão linear ( $\boldsymbol{\sigma}^{2}$ ERros, $\boldsymbol{\sigma}_{\text {ERros }}, \overline{\mathbf{X}}_{\text {ERRo }}$ ), número de avaliações superestimadas e subestimadas, sem e com auxílio da escala diagramática para avaliar severidade da pústula bacteriana

\begin{tabular}{|c|c|c|c|c|c|c|c|}
\hline \multirow{2}{*}{\multicolumn{2}{|c|}{ Avaliador }} & \multicolumn{4}{|c|}{ Erros } & Super & Sub \\
\hline & & \multirow{2}{*}{$\frac{[]_{\text {ERROS }}}{-0.90 ; 38.56}$} & \multirow{2}{*}{$\begin{array}{c}\boldsymbol{\sigma}_{\text {ERROS }}^{2} \\
136.65\end{array}$} & \multirow{2}{*}{$\begin{array}{c}\boldsymbol{\sigma}_{\text {ERROS }} \\
11.69\end{array}$} & \multirow{2}{*}{$\begin{array}{c}\overline{\mathbf{X}}_{\text {ERROS }} \\
-7.12 \mathrm{E}-16\end{array}$} & \multicolumn{2}{|c|}{ Estimados } \\
\hline 1 & Sem escala & & & & & 38 & 1 \\
\hline \multirow{2}{*}{2} & Sem escala & $-2.53 ; 38.55$ & 154.31 & 12.42 & $-1.55 \mathrm{E}-16$ & 37 & 2 \\
\hline & Com escala & $-8.60 ; 3.93$ & 6.58 & 2.56 & $1.28 \mathrm{E}-16$ & 17 & 20 \\
\hline 3 & Com escala & $-8.60 ; 14.10$ & 13.25 & 3.64 & $1.08 \mathrm{E}-17$ & 13 & 24 \\
\hline \multirow{2}{*}{4} & Sem escala & $-2.36 ; 22.40$ & 49.54 & 7.04 & $1.45 \mathrm{E}-17$ & 31 & 8 \\
\hline & Com escala & $-5.57 ; 3.10$ & 2.17 & 1.47 & $-2.83 \mathrm{E}-17$ & 13 & 23 \\
\hline \multirow{2}{*}{5} & Sem escala & $2.53 ; 34.48$ & 105.19 & 10.26 & $4.15 \mathrm{E}-16$ & 39 & 0 \\
\hline & Com escala & $-3.53 ; 4.00$ & 2.96 & 1.72 & $-3.61 \mathrm{E}-17$ & 15 & 23 \\
\hline \multirow{2}{*}{7} & Sem escala & $-4.36 ; 33.55$ & 101.25 & 10.06 & $-4.42 \mathrm{E}-16$ & 27 & 12 \\
\hline & Com escala & $-8.60 ; 3.93$ & 6.58 & 2.56 & $1.28 \mathrm{E}-16$ & 17 & 20 \\
\hline \multirow{2}{*}{8} & Sem escala & $-2.70 ; 28.55$ & 50.28 & 7.09 & 4.74E-16 & 35 & 3 \\
\hline & Com escala & $-7.36 ; 10.63$ & 10.84 & 3.29 & $-5.84 \mathrm{E}-17$ & 20 & 17 \\
\hline
\end{tabular}




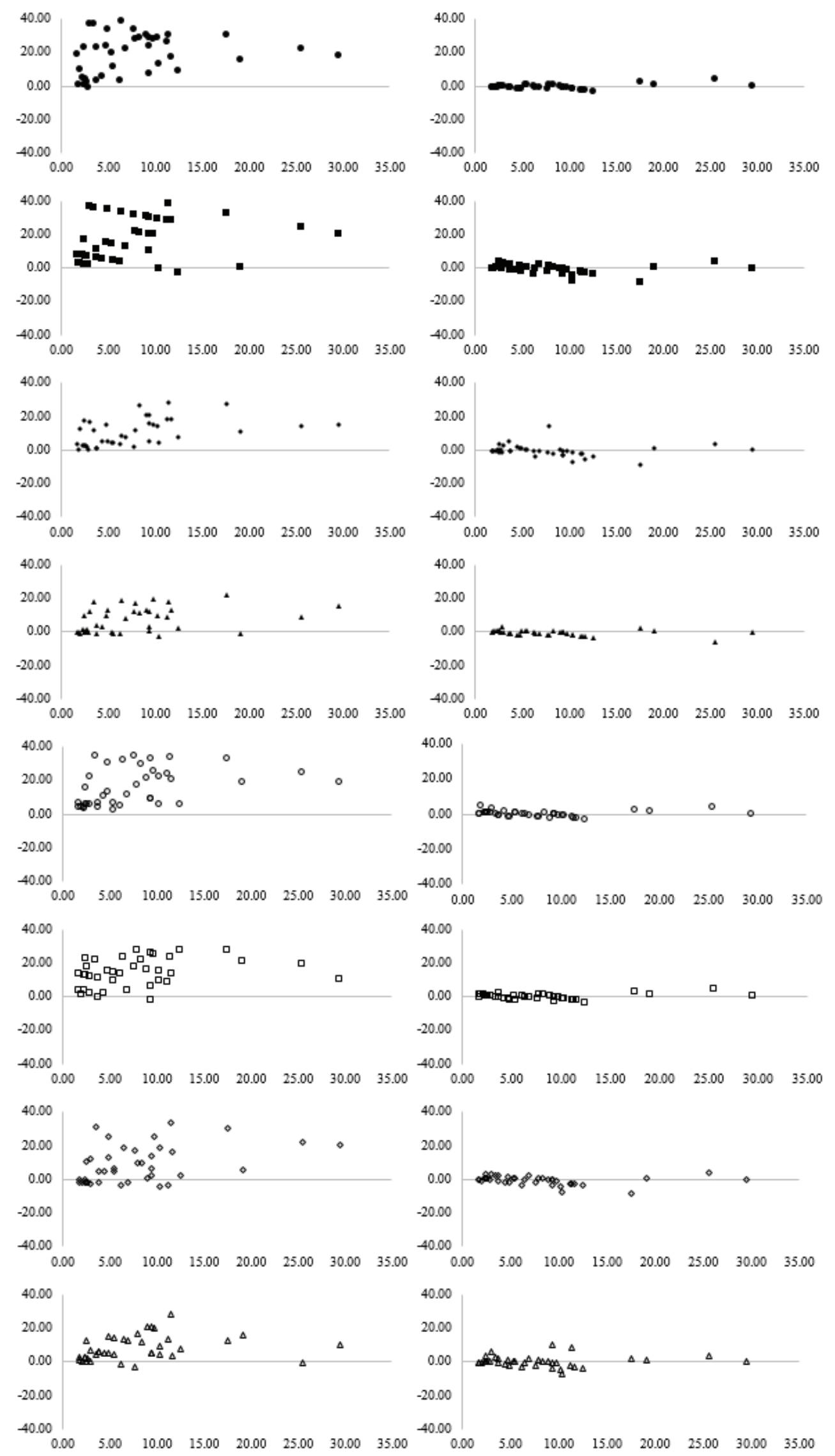

Figura 2. Erros absolutos (severidade estimada menos a severidade real) das avaliações da doença de oito avaliadores, sem (esquerda) e com

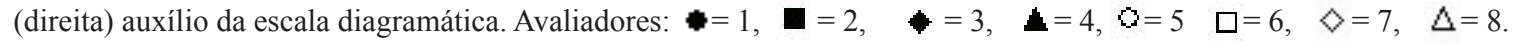


Utilizando a escala, o avaliador 4, superestimou e subestimou em 13 e 23 avaliações a severidade, respectivamente, mas houve a redução na magnitude destes desvios, sendo o intervalo de variação para os mesmos entre $-5,57$ e 3,10 .

Com o uso da escala proposta, foi nítida a diminuição da variância dos erros dos avaliadores. A maior estimativa da variância dos erros, sem a utilização da escala diagramática, foi encontrada para o avaliador dois $\left(\sigma^{2}\right.$ ERROS $\left.: 154,31\right)$ e este mesmo avaliador, usando a escala, teve redução em mais ou menos vinte e três vezes $\left(\sigma^{2}{ }_{\text {ERROS }}: 6,58\right)$. O intervalo dos resíduos, sem o uso da escala, variou de $-2,53$ a 38,55, apresentando uma amplitude de 41,08 reduzindo para 12,53 com o uso da escala (Tabela 2). Malagi et al. (8), observaram a mesma tendência dos avaliadores antes e depois do uso da escala, em estudo para validação de escala diagramática da mancha branca no milho.

A superestimação dos valores de severidade sem o uso de escala pelos avaliadores e a subestimação com o uso da mesma também foi observada por Godoy et al. (4) na avaliação da ferrugem asiática da soja. Já Soares et al. (12), avaliando a escala diagramática para avaliação da mancha alvo em soja, a qual provoca lesões foliares grandes, não observou uma tendência acentuada em superestimar ou subestimar a severidade desta doença. Sherwood et al. (11) concluíram que a percepção humana tem maior tendência em superestimar a severidade em área com maior número de lesões pequenas, do que a mesma área com menor número de lesões grandes.

Conclui-se que a utilização da escala diagramática desenvolvida resultou em melhor acurácia e precisão das estimativas realizadas, sendo uma ferramenta que pode ser adotada para quantificar a severidade da pústula bacteriana da soja.

\section{REFERÊNCIAS}

1. Amorim, L.; Bergamin Filho, A. Fenologia, patometria e quantificação de danos. In: Amorim, L.; Rezende, J.A.M.; Bergamin Filho, A. Manual de fitopatologia. 5.ed. Ouro Fino: Agronômica Ceres, 2018. cap. 39, p. 499-518.

2. Bonaldo, S. M.; Riedo, I. C.; Lima, A. R. Monitoramento e diagnóstico de doenças foliares da cultura da soja na região da COMCAM na safra de
2007/2008. Campo Digital, Campo Mourão, v. 4, n. 1, p. 127-136, 2009.

3. Chatnaparat, T.; Prathuangwong, S.; Lindow, S. E. Global pattern of gene expression of Xanthomonas axonopodis pv. glycines within soybean leaves. Molecular Plant Microbe Interactions, v. 29, n. 6, p. 508-522, 2016. DOI: 10.1094/MPMI-01-16-0007-R.

4. Godoy, C. V.; Koga, L. J.; Canteri, M. G. Diagrammatic scale for assessment of soybean rust severity. Fitopatologia Brasileira, Brasilia, v. 31, n. 1, p. 63-68, 2008.

5. Henning, A. A.; Almeida, A. M. R.; Godoy, C. V.; Seixas, C. D. S.; Yorinori, J. T.; Costamilan, L. M.; Ferreira, L. P.; Meyer, M. C.; Soares, R. M.; Dias, W. P. Manual de identificação de doenças de soja. 5.ed. Londrina: Embrapa Soja, 2014.

6. Horsfall, J. G.; Barratt, R. W. An improved grading system for measuring plant diseases. Phytopathology, St. Paul, v. 35, n. 655, 1945.

7. Lanna Filho, R. Fitobactérias na cultura da soja. In: Lemes, E.; Castro, L.; Assis, R. Doenças da soja: melhoramento genético e técnicas de manejo. Campinas: Millennium, 2015. p. 81-92.

8. Malagi, G.; Santos, I.; Camochena, R. C.; Moccelin, R. Elaboração e validação da escala diagramática para avaliação da mancha branca do milho. Revista Ciência Agronômica, Fortaleza, v. 42, n. 3, p. 797-804, 2011.

9. MAPA - Ministério da Agricultura, Pecuária e Abastecimento. 2019. Registro Nacional de Cultivares (RNC). Disponível em: $<$ http://sistemas. agricultura.gov.br/snpc/cultivarweb/cultivares_registradas.php $>$. Acesso em: 10 jan. de 2019.

10. Sain, S. K.; Gour, H. N. Pathological and physio-biochemical characterization of Xanthomonas axonopodis pv. glycines, incitent of Glycine max leaf pustules. Indian Phytopathology, New Delhi, v. 66, n. 1, p. 20-27, 2013.

11. Sherwood, R. T.; Berg, C. C.; Hoover, M. R.; Zeiders, K. E. Illusions in visual assessment of stagonospora leaf spot of orchardgrass. Phytopathology, St. Paul, v. 73, n. 2, p. 173-177, 1983.

12. Soares, R. M.; Godoy, C. V.; Oliveira, M. C. N. Escala diagramática para avaliação da severidade da mancha alvo da soja. Tropical Plant Pathology, Brasilia, v. 34, n. 5, p. 333-338, 2009.

13. Vernetti, F. J.; Vernetti Junior, F.J. Genética da soja: caracteres qualitiativos e diversidade genética. Brasília, DF: Embrapa Informação Tecnológica, 2009. 221p.

14. Violatti, M. R.; Tebaldi, N. D. Detecção de Xanthomonas axonopodis pv. glycines em sementes de soja. Summa Phytopathologica, Botucatu, v. 42, n. 3, p. 268-270, 2016. DOI: 10.1590/0100-5405/2127

15. Yorinori, J.T.; Yuyama, M.M.; Siqueri, F.V.; Araújo Júnior, I.P. Doenças na soja. In: Boletim de Pesquisa 2015/2016. Fundação Mato Grosso. Santa Cruz do Sul: Ed. Gazeta, 2015. p. 310-393. 